\title{
Effects of low temperature and cold- acclimation on photoinhibition and singlet oxygen production in four natural accessions of Arabidopsis
}

Heta Mattila\#1 ${ }^{\# 1}$ Kumud B. Mishra ${ }^{\# 2}$, liris Kuusisto ${ }^{1}$, Anamika Mishra ${ }^{2}$, Kateřina Novotná ${ }^{2}$ David Šebela ${ }^{2}$, Esa Tyystjärvi ${ }^{1}$

"Equal contribution

${ }^{1}$ Department of Biochemistry/Molecular Plant Biology/ University of Turku/ Turku/ 20014/ Finland

${ }^{2}$ Global Change Research Institute CAS, Bělidla 986/4a/ Brno/ 603 00/ Czech Republic

*Corresponding author, esatyy@utu.fi, +358 294504202

\section{Author contributions}

ET, KBM and HM conceived and designed research. HM, KBM, IK, AM, KN and DŠ conducted experiments. $\mathrm{HM}, \mathrm{ET}$ and $\mathrm{KBM}$ analyzed data. $\mathrm{HM}$ wrote the manuscript with contributions from $\mathrm{ET}$ and KBM. All authors read and approved the manuscript

\section{Acknowledgements}

This work was supported by Academy of Finland (grant 307335; to E.T.), Turku University Foundation (12353; to H.M.), University of Turku Graduate School (to H.M.), Vilho, Yrjö and Kalle Väisälä Foundation (to H.M.), European Union COST Action (TD1102; to E.T., H.M. and K.B.M.), the Ministry of Education, Youth and Sports of CR within the National Sustainability Program I (NPU I, LO1415; to K.B.M., A.M., K.A. and D.S.) and the project "SustES - Adaptation strategies for sustainable ecosystem services and food security under adverse environmental conditions"

(CZ.02.1.01/0.0/0.0/16_019/0000797; to K.B.M.). 


\section{Main conclusions}

- Low temperature decreases PSII damage in vivo, in agreement with earlier in vitro results.

- Susceptibility to photoinhibition differs among Arabidopsis accessions and moderately decreases after cold-acclimation.

- Flavonols may alleviate photoinhibition.

\section{Abstract}

To understand the effects of low temperature and cold-acclimation on reactive oxygen species and photoinhibition of photosystem II (PSII), light-induced inactivation of PSII was measured at 22 and 4 ${ }^{\circ} \mathrm{C}$ from four Arabidopsis thaliana accessions (Rschew, Tenela, Columbia-0 and Coimbra) grown under optimal conditions. Photoinhibition was also measured at $4{ }^{\circ} \mathrm{C}$ from plants cold-acclimated at $4{ }^{\circ} \mathrm{C}$ for two weeks. Measurements were done in the absence and presence of lincomycin that blocks PSII repair, and PSII activity was assayed with the ratio of variable to maximum chlorophyll $a$ fluorescence $\left(F_{v} / F_{M}\right)$ and with light-saturated rate of oxygen evolution using a quinone acceptor. Of the nonacclimated accessions, Rschew was the most tolerant to photoinhibition and Coimbra the least; the rate constants of photoinhibition of the most sensitive accession were 1.3-1.9 times as high as those of the tolerant ones. The damaging reaction of photoinhibition in non-acclimated plants was slower or equal at $4{ }^{\circ} \mathrm{C}$ than at $22^{\circ} \mathrm{C}$. The rate constants of photoinhibition of cold-acclimated plants, at $4{ }^{\circ} \mathrm{C}$, were 0.55 to 1.25 times as high as those of non-acclimated plants; the protective effect of coldacclimation on photoinhibition was consistent in Columbia- 0 and Coimbra whereas Rschew and Tenela were either slightly more tolerant or susceptible, depending on the method used to assay photoinhibition. Production of singlet oxygen, measured from thylakoid membranes isolated from non-acclimated and cold-acclimated plants, did not decrease due to cold-acclimation, nor did singlet oxygen production correlate with the rate of photoinhibition or with flavonol contents of the leaves.

\section{Keywords:}

Acclimation, charge recombination, chilling stress, hardening, photodamage, photoinactivation 


\section{Introduction}

Light is the energy source of plants, but Photosystem II (PSII) is also damaged by light, and synthesis of a new D1-protein is needed for the recovery of the electron transfer activity of PSII (for reviews, see Tyystjärvi 2013; Nath et al. 2013). The initial rate of the damage is directly proportional to the intensity of light (Tyystjärvi and Aro 1996), and when damage is faster than repair, e.g. under high light, non-functional PSII units accumulate. In the literature, the term "photoinhibition" has been used to describe several phenomena; here we strictly refer to the light-induced irreversible loss of activity of PSII. The molecular mechanism of the damage to PSII is still under debate (Tyystjärvi 2013).

Low temperature is one of the major factors limiting growth and geographical distribution of plant species. The repair of PSII slows down if temperature drops (Greer et al. 1986; Salonen et al. 1998; Grennan and Ort 2007). Results about the effect of temperature on the rate of the damage itself, however, vary. A decrease in the rate of damage with a decrease in temperature in pumpkin thylakoids (Tyystjärvi et al. 1994; Tyystjärvi 2013) and chloramphenicol-treated leaves (Tyystjärvi 1993), lack of a clear temperature dependence in the cyanobacterium Synechocystis (Allakhverdiev and Murata 2004), and an increase in the rate of damage with decreasing temperature in the leaves of cucumber (Sonoike et al. 1999), Chenopodium album (Tsonev and Hikosaka 2003) and cotton (Kornyeyev et al. 2003) have been reported. According to the "excitation pressure" hypothesis (Sonoike et al. 1999; Kornyeyev et al., 2003) photoinhibition is expected to increase with decreasing temperature because light absorption and subsequent charge separation are almost temperatureindependent but the sink capacity decreases with temperature because carbon fixation slows down (Abat and Deswal 2009; for a review, see Yamori et al. 2014). The "over-reduction" of electron transfer chain may increase singlet oxygen $\left({ }^{1} \mathrm{O}_{2}\right)$ production because reduced electron acceptors promote PSII charge recombination reactions. ${ }^{1} \mathrm{O}_{2}$, in turn, could then damage PSII (see e.g. Triantaphylidès and Havaux 2009; Vass and Cser 2009). Photosystem I (PSI) is usually less susceptible to light-induced damage than PSII (Tyystjärvi et al. 1989), but also photoinhibition of PSI was reported in some cold-susceptible species at low temperatures (Sonoike et al. 1999).

Prolonged exposure to low but non-freezing temperatures triggers cold-acclimation in several plant species, causing large changes in gene expression and modifying multiple physiological processes, including synthesis of protective substances, changes in the composition of membrane lipids (e.g. Murata et al. 1992), and changes in enzyme activities or amounts of other substances protecting against reactive oxygen species (ROS). Eventually cold-acclimation allows them to survive or grow at even lower temperatures than required for acclimation, but the improvement of the cold-tolerance is species-specific (for a review, see e.g. Theocharis et al. 2012; Crosatti et al. 2013). Light plays an important role in the development of full cold-acclimation (Soitamo et al. 2008), and it has been suggested that plants respond to coldness partly through sensing and responding to the reduced electron transfer chain (Gray et al. 1996; Ivanov et al. 2006; Crosatti et al. 2013).

Cold-acclimation (Somersalo and Krause 1989; Gray et al. 1996; Krause et al. 1999; Savitch et al. 2000; Venema et al. 2000; Sane et al. 2003; Shang et al. 2003) or over-expression of cold-inducible genes (Yang et al. 2010) have been reported to attenuate photoinhibition of PSII at low temperatures. In some species this is due to increased activity of the repair cycle of PSII (Krause et al. 1999; Venema et al. 2000; Shang et al. 2003; Grennan and Ort 2007; Rogalski et al. 2008) but also the rate of the damaging reaction of photoinhibition has been reported to diminish due to coldacclimation (Vonshak and Novoplansky 2008). The protection has been hypothesized to be based on the ability of cold-acclimated plants to keep the $Q_{A}$ electron acceptor of PSII more oxidized in the light even at low temperature (Öquist et al. 1993; Gray et al. 1996). Cold-acclimation can increase the activities of the enzymes of the Calvin-Benson cycle, which leads to an increase in the rates of carbon fixation at low temperatures (Hurry et al. 1994; Strand et al. 1999). Alternative electron transfer 
routes (cyclic electron transfer and electron transfer to the plastid terminal oxidase) may also function more efficiently after cold-acclimation (e.g. Ivanov et al. 2012; Mishra et al. 2019). In many plant species, cold-acclimation also leads to changes in the redox potentials of the electron transport chain of PSII, possibly modifying recombination reactions and ${ }^{1} \mathrm{O}_{2}$ yield (Janda et al. 2000; Ivanov et al. 2001; Sane et al. 2003).

The amounts of xanthophyll pigments and/or non-photochemical quenching of excitation energy (NPQ) can increase during cold-acclimation (e.g. Krause et al. 1999; Venema et al. 2000). In the case of cold-tolerant plants, protection by NPQ against low-temperature-induced photoinhibition may, however, be important only in short-term cold-stress (Havaux and Kloppstech 2001). Furthermore, cold-acclimation may affect the concentrations of anthocyanins and flavonols. Although in the vacuole, flavonols have been found in chloroplasts of several species (Saunders and McClure 1976). In Phillyrea latifolia chloroplast-envelope-located flavonols were reported to quench ${ }^{1} \mathrm{O}_{2}$ (Agati et al. 2007). Flavonols are preferentially located at the lipid-water interphase (Scheidt et al. 2004), which allows them to quench ${ }^{1} \mathrm{O}_{2}$ produced within the membrane. These properties may make flavonols important scavengers of ${ }^{1} \mathrm{O}_{2}$, as the lifetime of ${ }^{1} \mathrm{O}_{2}$ in plant cells is so short (for reviews, see Mattila et al. 2015; Arellano and Naqvi 2016) that the damage caused by ${ }^{1} \mathrm{O}_{2}$ is expected to occur near the site of origin of this ROS (Moan 1990).

Arabidopsis thaliana grows over a broad geographic range with varying temperatures, and therefore, effects of low temperature and cold-acclimation on photoinhibition can be investigated in natural accessions of this model plant species. In the present study, we used four accessions (Rschew, Tenela, Columbia- 0 and Coimbra) with different cold-acclimation capacities. Previous investigations on photoinhibition of PSII at low temperatures have mostly been conducted by illuminating plants in the absence of a translation inhibitor (Gray et al. 1996; Krause et al. 1999; Venema et al. 2000; Sane et al. 2003). Thus, it is not clear whether the observed changes in photoinhibition depend on differences in the rate of damage or repair. Moreover, previous reports investigating the effect of coldacclimation on photoinhibition of PSII have mostly used only chlorophyll $a$ fluorescence to assay photoinhibition (e.g. Gray et al. 1996; Krause et al. 1999; Venema et al. 2000; Sane et al. 2003). In the present study, to differentiate between NPQ, repair and damage, we illuminated leaves in the presence and absence of the chloroplast translation inhibitor, lincomycin, and assayed photoinhibition by chlorophyll $a$ fluorescence as well as by oxygen evolution. In addition, ${ }^{1} \mathrm{O}_{2}$ production was measured to understand the effects of cold-acclimation and this ROS on photoinhibition.

\section{Materials and methods}

\subsection{Growth conditions}

A. thaliana accessions, Rschew, Tenela, Columbia-0, and Coimbra, were grown in a growth chamber (FytoScope FS-RI 1600, Photon Systems Instruments, Brno, Czech Republic) for six weeks at day/night temperatures of $21^{\circ} \mathrm{C} / 18{ }^{\circ} \mathrm{C}$, with day/night light rhythm of $8 \mathrm{~h} / 16 \mathrm{~h}$ (photosynthetic photon flux density, PPFD, of $100 \mu \mathrm{mol} \mathrm{m} \mathrm{m}^{-2}$ ) with $\sim 60 \%$ humidity, as described in Mishra et al. (2014). After six weeks of growth, half of the plants were shifted for cold-acclimation at $4{ }^{\circ} \mathrm{C}$ for two weeks (ACC) while the rest of the plants (NAC) were kept in the same conditions as before.

\subsection{Pigments}

Chlorophyll and flavonol contents were measured from intact leaves with a nondestructive handheld device (Dualex Scientific, Force-A, Paris, France) after seven to eight weeks of growth. At least three individual uniform-sized NAC and ACC plants of each accession were selected, from which three fully expanded leaves were measured. 


\subsection{Gas exchange measurements}

Net $\mathrm{CO}_{2}$ assimilation rates of individual attached leaves of NAC and ACC plants of each accession, after seven to eight weeks of growth, were measured with a gas exchange measuring system LI-640017 (Li-Cor, Biosciences, Linkoln, Nebraska, USA) using a 6400-15 Arabidopsis chamber of aperture diameter of $1 \mathrm{~cm}$ (Li-Cor, Biosciences, Linkoln, Nebraska, USA). $\mathrm{CO}_{2}$ concentration in the chamber was set to $385 \mathrm{ppm}$, air humidity to $60 \pm 5 \%$ and temperature to $22^{\circ} \mathrm{C}$. Light-acclimated leaves were illuminated first for $2 \mathrm{~min}$ at the PPFD of $100 \mu \mathrm{mol} \mathrm{m}^{-2} \mathrm{~s}^{-1}$ and then for $45 \mathrm{~min}$ at the PPFD of 2000 $\mu \mathrm{mol} \mathrm{m} \mathrm{m}^{-2} \mathrm{~s}^{-1}$.

\subsection{Photoinhibition measurements}

After eight weeks of growth, detached leaves, with petioles under water, were illuminated for 0-45 min at the PPFD of $2000 \mu \mathrm{mol} \mathrm{m} \mathrm{m}^{-1}$ at $22^{\circ} \mathrm{C}$ or $4{ }^{\circ} \mathrm{C}$ in a growth chamber (FytoScope FS 130, Photon Systems Instruments, Brno, Czech Republic). To prevent the repair cycle of PSII, leaf petioles were incubated overnight in lincomycin $(0.4 \mathrm{mg} / \mathrm{ml})$ solution, under the low irradiance of $\sim 10 \mu \mathrm{mol} \mathrm{m} \mathrm{m}^{-2} \mathrm{~s}^{-1}$. Before and after the treatment, leaves were kept for $30 \mathrm{~min}$ in dark at $22^{\circ} \mathrm{C}$, after which the chlorophyll $a$ fluorescence parameter, $\mathrm{F}_{\mathrm{v}} / \mathrm{F}_{\mathrm{M}}$ (variable to maximum fluorescence), was measured by Handy Fluorcam FC 1000-H (Photon System Instruments, Brno, Czech Republic). After the fluorescence measurements, thylakoid membranes from 3-6 leaves were isolated as described by Hakala et al. (2005) and immediately stored at $-80^{\circ} \mathrm{C}$. PSIl activity was then measured with a method parallel to fluorescence, by measuring the light-saturated rate of oxygen evolution from the thylakoid membranes with an oxygen electrode (Hansatech, King's Lynn, UK) as described by Hakala et al. (2005) using $0.5 \mathrm{mM} \mathrm{2,6-dimethylbenzoquinone} \mathrm{as} \mathrm{an} \mathrm{electron} \mathrm{acceptor.} \mathrm{Chlorophyll} \mathrm{concentration}$ of isolated thylakoid membranes was measured according to Porra et al. (1989). Whenever lincomycin was used, the rate constant of photoinhibition $\left(k_{P I}\right)$ was calculated by fitting the decrease in $\mathrm{F}_{\mathrm{V}} / \mathrm{F}_{\mathrm{M}}$ or in the rate of oxygen evolution, as indicated, to the first order reaction equation.

\section{5. ${ }^{1} \mathrm{O}_{2}$ and thermoluminescence measurements}

The rate of ${ }^{1} \mathrm{O}_{2}$ production of isolated thylakoid membranes $(100 \mu \mathrm{g} \mathrm{chl} / \mathrm{ml})$ in high light (PPFD 4000 $\mu \mathrm{mol} \mathrm{m} \mathrm{m}^{-2} \mathrm{~s}^{-1}$ ), at $4{ }^{\circ} \mathrm{C}$ or at $22^{\circ} \mathrm{C}$, was estimated by measuring the consumption of oxygen by $20 \mathrm{mM}$ histidine (Telfer et al. 1994, Rehman et al. 2013) as described in Karonen et al. (2014).

Thermoluminescence bands were recorded with a luminometer from isolated thylakoid membranes $(500 \mu \mathrm{g} \mathrm{chl} / \mathrm{ml})$ as described earlier (Tyystjärvi et al. 2009) in the presence or absence of $20 \mu \mathrm{M} 3-$ (3,4-dichlorophenyl)-1,1-dimethylurea (DCMU), as indicated. The thylakoid membranes for ${ }^{1} \mathrm{O}_{2}$ and thermoluminescence measurements were isolated as described above from NAC and ACC plants taken directly from growth chambers.

\subsection{Statistical tests and figures}

Significances of differences were tested by calculating Student's t-test (two-tailed, unequal variances). Fitting of photoinhibition to the first order reaction equation were done in SigmaPlot (Systat Software, Inc) as well as all figures.

\section{Results}

\subsection{Assaying photoinhibition of PSII, in the presence of repair, by chlorophyll $a$ fluorescence}

Detached leaves from non-acclimated (NAC) A. thaliana accessions (Rschew, Tenela, Columbia-0 and Coimbra) were given a high light treatment (PPFD of $2000 \mu \mathrm{mol} \mathrm{m}^{-2} \mathrm{~s}^{-1}$ ) either at their growth 
temperature (at $22^{\circ} \mathrm{C}$ ) or at $4{ }^{\circ} \mathrm{C}$. We measured maximum quantum yield of PSII photochemistry ( $\mathrm{FV}_{\mathrm{V}} / \mathrm{F}_{\mathrm{M}}$; after $20 \mathrm{~min}$ of dark-incubation) during the $0-45 \mathrm{~min}$ high light treatment (Fig. 1A-B). Illumination was conducted in the absence of lincomycin to allow the repair of the D1-protein to proceed simultaneously with photoinhibitory damage to PSII. In addition, leaves from plants coldacclimated (ACC) for two weeks at $4{ }^{\circ} \mathrm{C}$ were illuminated under the same high light at $4{ }^{\circ} \mathrm{C}$ (Fig. 1C). Of the four accessions, Coimbra and Rschew seemed the most susceptible and tolerant to photoinhibition of PSII, respectively (Fig. 1). In NAC plants, on the average, $\mathrm{Fv}_{\mathrm{v}} / \mathrm{F}_{\mathrm{M}}$ values declined faster at $4{ }^{\circ} \mathrm{C}$ than at $22^{\circ} \mathrm{C}$ (Figs. $1 \mathrm{~A}-\mathrm{B}$ ), although the difference was statistically significant only for Tenela after $15 \mathrm{~min}(P=0.03)$ and $30 \mathrm{~min}(P=0.01)$ and for Rschew after $45 \mathrm{~min}(P=0.01)$ of the light treatment. However, the rate of photoinhibition at $4{ }^{\circ} \mathrm{C}$ did not differ significantly between NAC and ACC plants in any of the accessions.

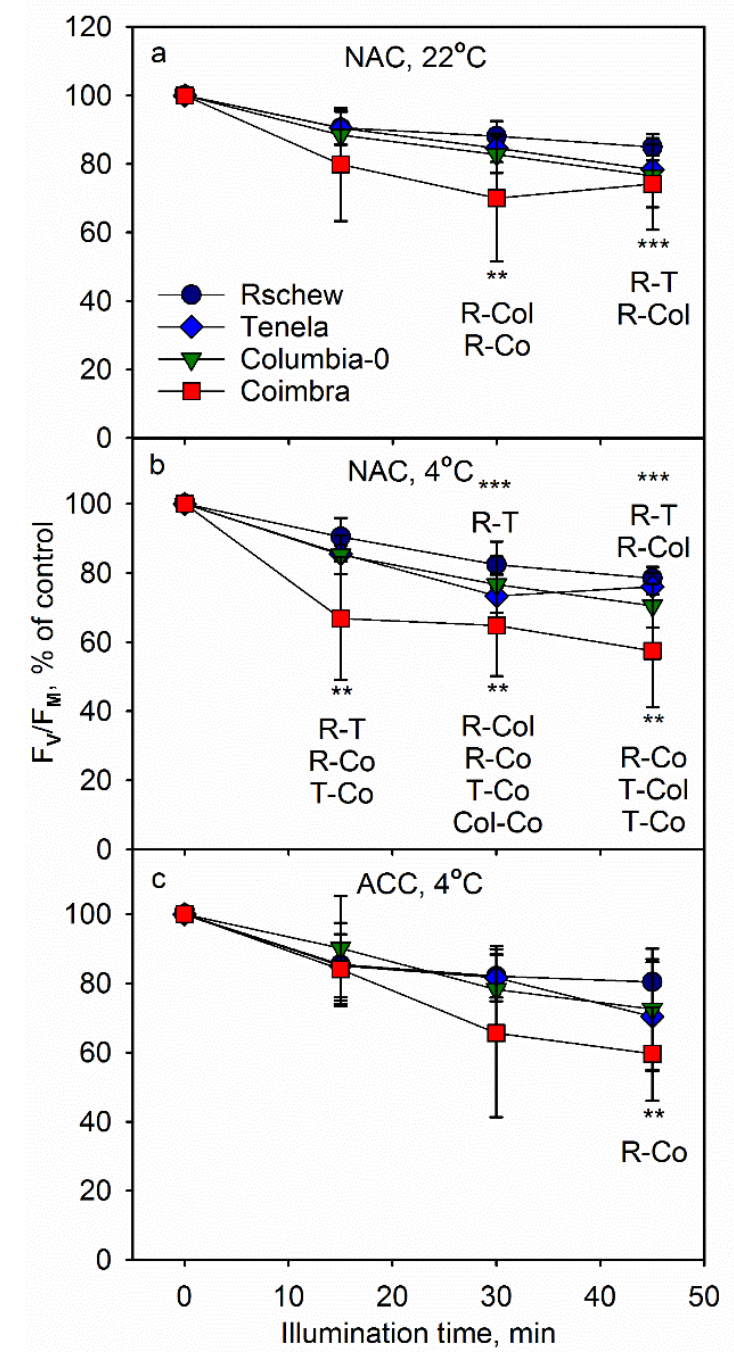

Fig. 1 Photoinhibition, quantified by the chlorophyll $a$ fluorescence parameter $\mathrm{F}_{\mathrm{V}} / \mathrm{F}_{\mathrm{M}}$, at $22{ }^{\circ} \mathrm{C}$ (a) or at $4{ }^{\circ} \mathrm{C}(b-c)$ in the absence of lincomycin. $\mathrm{F}_{\mathrm{V}} / \mathrm{F}_{\mathrm{M}}$ was measured from detached leaves of four nonacclimated (NAC; $a-b$ ) or cold-acclimated (ACC; $c) A$. thaliana accessions, at different time points during the 45-min illumination (PPFD $2000 \mu \mathrm{mol} \mathrm{m}^{-2} \mathrm{~s}^{-1}$ ) and subsequent 30-min dark incubation. The error bars show standard deviations (SD) from at least three biological replicates. Statistically significant differences at any time-point between the indicated accessions are marked with $* * *(P<$ $0.01)$ or $* *(P<0.05)$. The control values of $F_{V} / F_{M}( \pm S D)$ were $0.82(0.03), 0.80(0.03), 0.82(0.03)$ and $0.76(0.05)$ for Rschew (R), Tenela $(\mathrm{T})$, Columbia-0 (Col) and Coimbra (Co), respectively, in (a), 0.82 (0.03), $0.82(0.03), 0.81(0.04)$ and $0.79(0.06)$ in (b), and $0.82(0.03), 0.79(0.04), 0.77(0.08)$ and 0.79 (0.06) in (c) 


\subsection{Assaying photoinhibition of PSII, in the absence of repair, by chlorophyll $a$ fluorescence}

To see if the observed differences in photoinhibition were due to differences in the rate of damage to PSII or in the rate of repair, we repeated the experiments in the presence of lincomycin. In addition, the absence of the repair allows a decline in PSII activity (quantified by $F_{V} / F_{M}$ ) to be fitted to the first order reaction equation for calculation of the rate constant of photoinhibition of PSII ( $\left.k_{P I}\right)$.

Similarly as observed without lincomycin (Fig. 1), we found that Coimbra and Rschew were, respectively, the least and the most tolerant to photoinhibition, both at $22{ }^{\circ} \mathrm{C}$ and at $4{ }^{\circ} \mathrm{C}$ (Fig. $2 \mathrm{~A}-\mathrm{B}$, see Table 1 for the $k_{P I}$ values). However, in contrast to the experiments in which the repair was allowed to function, $\mathrm{F}_{\mathrm{V}} / \mathrm{F}_{\mathrm{M}}$ values declined more rapidly at $22{ }^{\circ} \mathrm{C}$ than at $4{ }^{\circ} \mathrm{C}$ in Columbia-0 $(P=0.02)$ and Coimbra $(P=0.05$ ) (Fig. $2 A-B)$. In Rschew and Tenela the differences were not statistically significant. In all four accessions, photoinhibition at $4{ }^{\circ} \mathrm{C}$ proceeded more slowly in ACC plants than in NAC plants (Fig. 2B-C) Accordingly, the $\mathrm{k}_{\mathrm{PI}}$ values of ACC Rschew, Tenela and Coimbra were circa $77 \%$ and of ACC Columbia-0 $84 \%$ of those of NAC plants (Table 1). The difference was significant in the case of Rschew $(P=0.0002)$ and Tenela $(P=0.01)$. The differences in photoinhibition tolerance were no longer statistically significant among the ACC accessions (Fig. 2C, Table 1). 


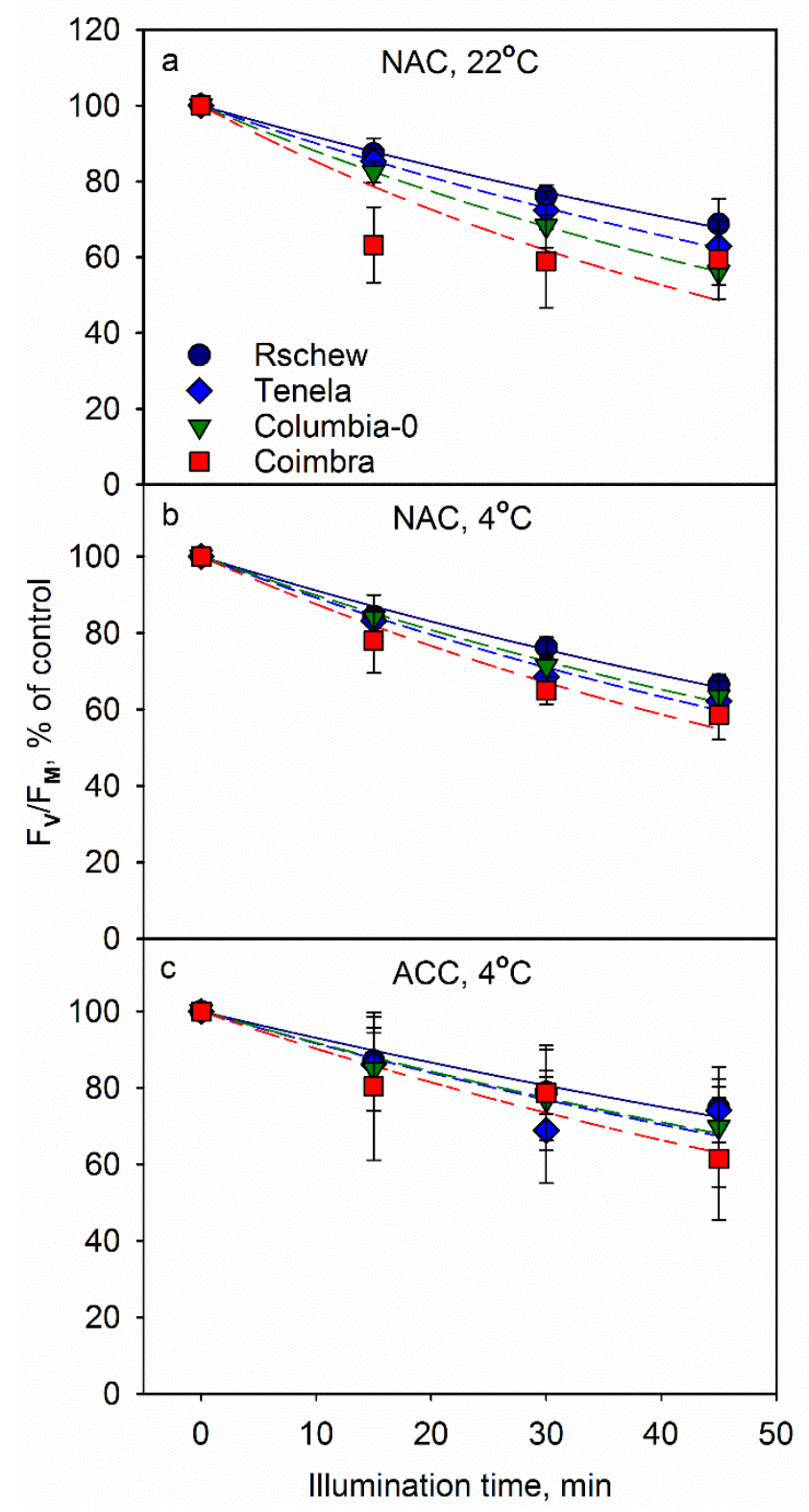

Fig. 2 Photoinhibition, quantified by the chlorophyll $a$ fluorescence parameter $F_{v} / F_{M}$, at $22^{\circ} \mathrm{C}$ (a) or at $4{ }^{\circ} \mathrm{C}(\mathrm{b}-\mathrm{c})$ in the presence of lincomycin. $\mathrm{F}_{\mathrm{V}} / \mathrm{F}_{\mathrm{M}}$ was measured from detached leaves of four nonacclimated (NAC; a-b) or cold-acclimated (ACC; c) A. thaliana accessions, at different time points during the 45-min illumination (PPFD $2000 \mu \mathrm{mol} \mathrm{m}^{-2} \mathrm{~s}^{-1}$ ) and subsequent 30-min dark incubation. The error bars show SD from at least three biological replicates. The control values of $F_{v} / F_{M}( \pm S D)$ were 0.82 (0.03), $0.79(0.05), 0.83(0.01)$ and 0.78 (0.04) for Rschew, Tenela, Columbia-0 and Coimbra, respectively, in (a), $0.80(0.01), 0.77(0.02), 0.81(0.03)$ and $0.79(0.03)$ in (b) and $0.82(0.03), 0.77$ (0.07), $0.79(0.06)$ and $0.79(0.06)$ in (c)

\subsection{Assaying photoinhibition of PSII, in the absence of repair, by oxygen evolution}

To test whether the results are universal or specific to a particular method of quantification of photoinhibition, we next assayed photoinhibition of PSII by measuring the light-saturated rate of oxygen evolution in the presence of an artificial electron acceptor from thylakoid membranes isolated from the illuminated leaves. 
Photoinhibition appeared faster when measured with oxygen evolution compared to that measured with the fluorescence parameter $F_{V} / F_{M}$ (c.f. Figs. 2-3; Table 1). However, similarly to the fluorescence data, we found that Rschew was the most tolerant accession and Coimbra the least, at both $4{ }^{\circ} \mathrm{C}$ and $22^{\circ} \mathrm{C}$ (Table 1). Furthermore, photoinhibition proceeded more slowly at $4{ }^{\circ} \mathrm{C}$ than at $22^{\circ} \mathrm{C}$ in all the accessions (Fig. 3A-B), although the differences in the $\mathrm{k}_{\mathrm{PI}}$ values (Table 1 ) were significant $(P<0.05)$ only for Rschew and Columbia-0. Cold-acclimation alleviated photoinhibition at $4{ }^{\circ} \mathrm{C}$ statistically significantly only in Coimbra (Fig. 3B-C). In Rschew and Tenela, the differences between the $\mathrm{k}_{\mathrm{PI}}$ values for ACC and NAC plants were not statistically significant.

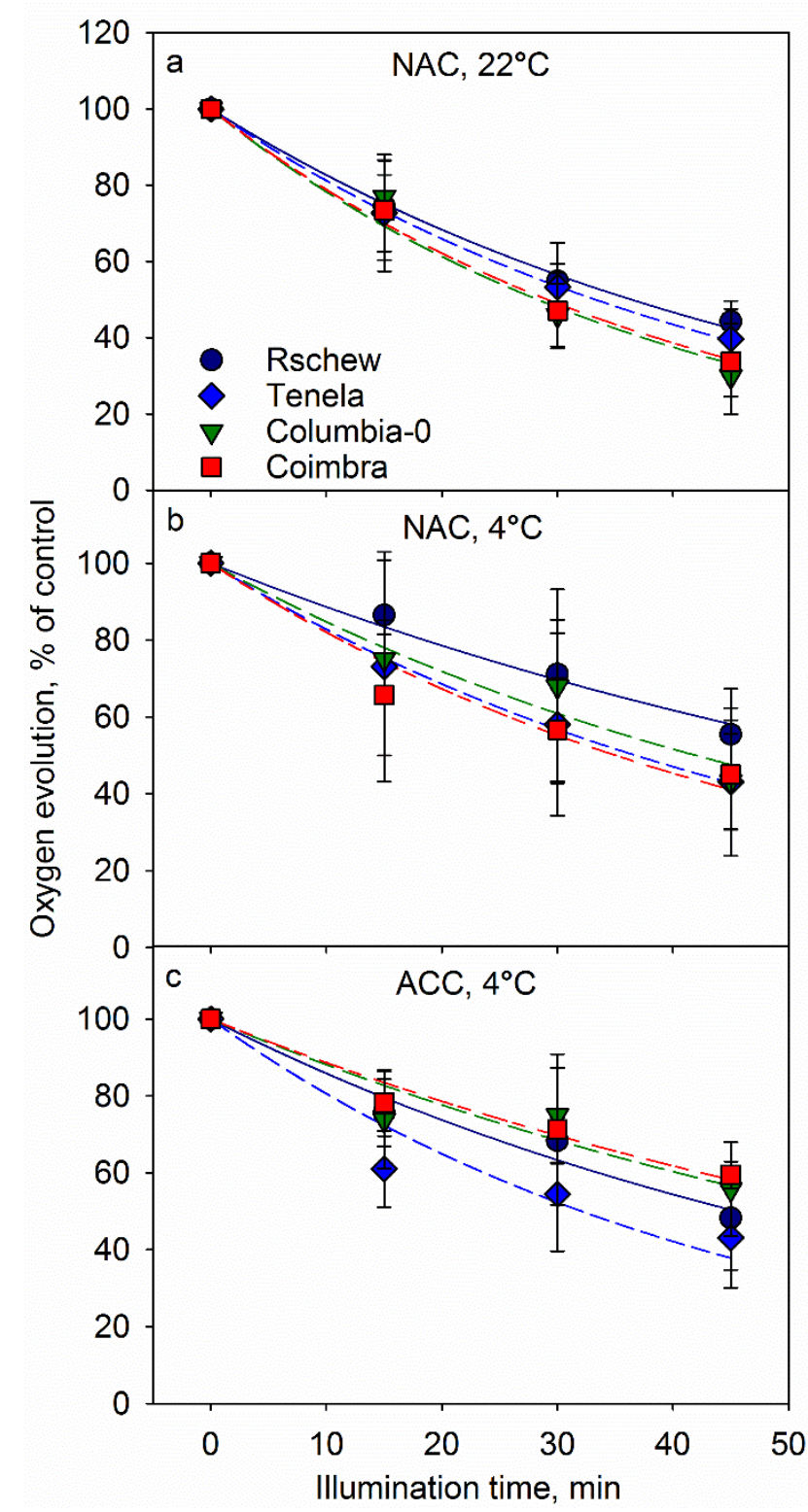

Fig. 3 Photoinhibition, quantified by the light-saturated oxygen evolution of PSII in the presence of an artificial electron acceptor, at $22^{\circ} \mathrm{C}(\mathrm{a})$ or at $4{ }^{\circ} \mathrm{C}(\mathrm{b}-\mathrm{c})$ in the presence of lincomycin. PSIl activity was measured from thylakoid membranes isolated from leaves of four non-acclimated (NAC; a-b) or coldacclimated (ACC; C) A. thaliana accessions, at different time points during the 45-min illumination (PPFD $2000 \mu \mathrm{mol} \mathrm{m}^{-2} \mathrm{~s}^{-1}$ ). The error bars show SD from at least four biological replicates. The control

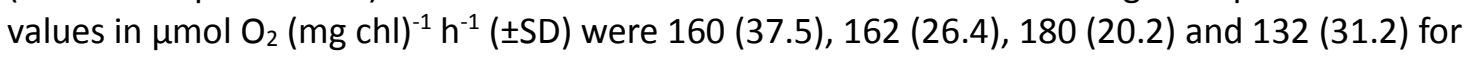
Rschew, Tenela, Columbia-0 and Coimbra, respectively, in (a), 169 (67.6), 148 (67.1), 162 (37.4) and 135 (24.7) in (b) and 210 (21.7), 186 (22.9), 164 (28.7) and 162 (37) in (c) 
Table 1 The rate constant of photoinhibition $\left(\mathrm{k}_{\mathrm{Pl}}\right)$ values in $\mathrm{min}^{-1}$ calculated by fitting the decline in $\mathrm{Fv} / \mathrm{F}_{\mathrm{M}}$ (Fig. 2) or in PSII-dependent oxygen evolution (Fig. 3) during the 45 -min illumination at $22^{\circ} \mathrm{C}$ or at $4{ }^{\circ} \mathrm{C}$, to the first order reaction equation in NAC and ACC $A$. thaliana accessions. SD values (in parentheses) were calculated from at least three biological replicates. Statistically significant differences $(P<0.05)$ between accessions are indicated with lower-case letters and between treatment groups (between NAC $22^{\circ} \mathrm{C}$ and NAC $4{ }^{\circ} \mathrm{C}$, or between NAC $4{ }^{\circ} \mathrm{C}$ and ACC $4{ }^{\circ} \mathrm{C}$ ) with uppercase letters. Significances of the differences between different accessions are shown only within the same treatment group. Significances of the differences between fluorescence and oxygen evolution data were not calculated

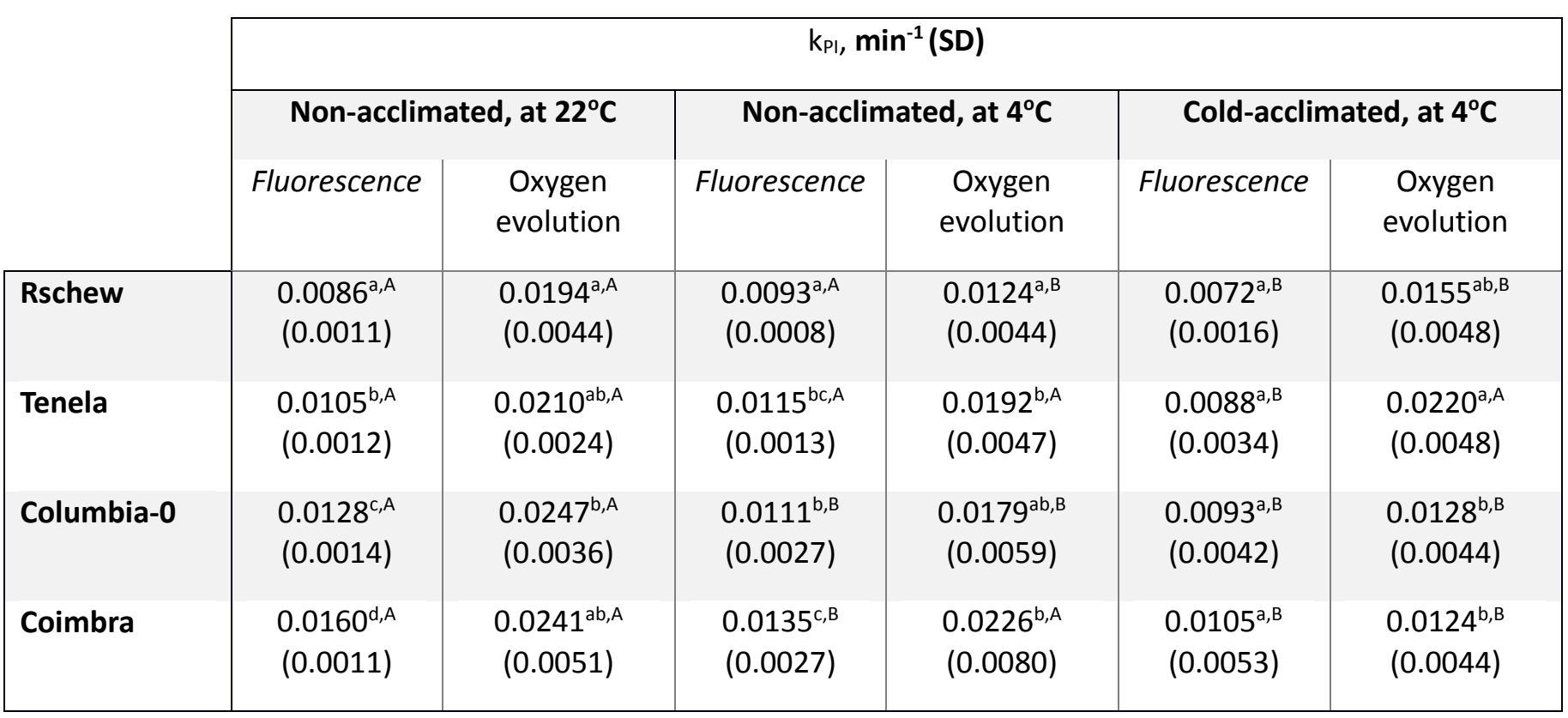

\subsection{Physiological parameters of cold-acclimated and non-acclimated plants}

To find the factors affecting the different photoinhibition tolerances of the accessions, we measured chlorophyll content, epidermal flavonols, photochemical reflectance index (PRI) and the rate of $\mathrm{CO}_{2}$ assimilation of intact leaves of NAC and ACC accessions, by using non-invasive instruments. Chlorophyll contents, measured per leaf area with an optical method, were only little affected by temperature, age or accession. Cold-acclimation caused slight decrease of the chlorophyll content after seven days at $4{ }^{\circ} \mathrm{C}$ only in Columbia-0 (Fig. 4A), and even in this accession, no statistically significant difference was observed after 14 days of the cold-acclimation. In NAC Rschew the chlorophyll content slightly increased during the 14 day time-frame of the experiment (Fig. 4A). The relative differences in the amounts of chlorophyll between the accessions (Rschew $>$ Columbia- $0>$ Tenela > Coimbra) stayed the same in all the treatment groups (Fig. 4A).

Contrary to chlorophylls, epidermal flavonols increased significantly during the cold-acclimation, both after 7 and 14 days, in all the four accessions (Fig. 4B). In Tenela and Coimbra the coldacclimation-induced increase in epidermal flavonols was lower than in Rschew and Columbia- 0 , and the difference was more obvious after 14 days of cold-acclimation (Fig. 4B). In Tenela and Coimbra, flavonols also increased when the NAC plants grew older (Fig. 4B). 


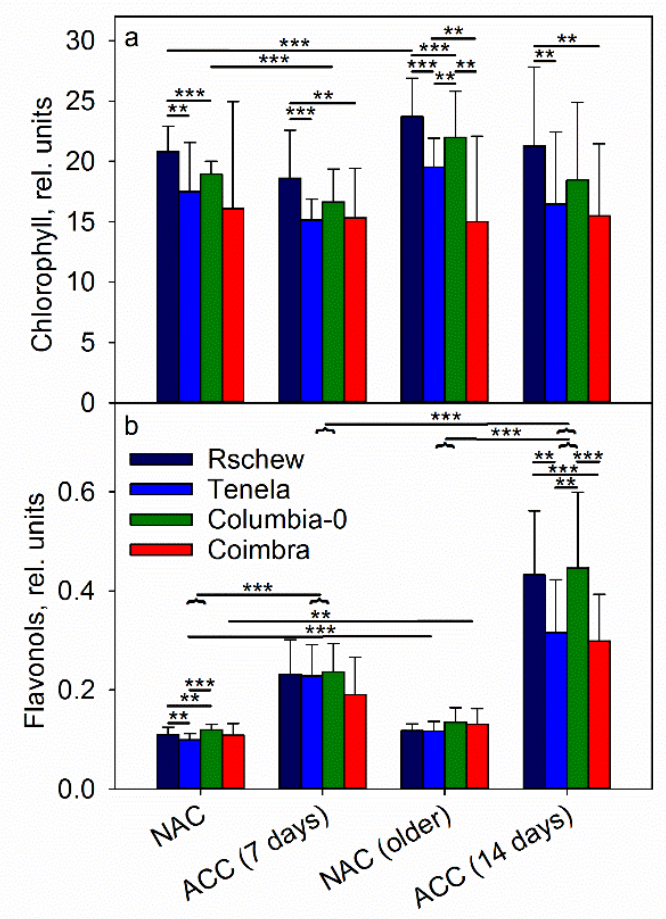

Fig. 4 Chlorophyll (a) and flavonol (b) contents measured from intact leaves of $A$. thaliana accessions (Rschew, Tenela, Columbia-0 and Coimbra) after 7 or 14 days, as indicated, of cold-acclimation at $4{ }^{\circ} \mathrm{C}$ (ACC) or from non-acclimated (NAC) control plants of similar ages. The error bars show SD values from at least four biological replicates. Statistically significant differences are marked with $* *(P<$ $0.05)$ or $* * *(P<0.01)$ on top of the horizontal lines that show between which samples the difference is significant; the horizontal curly bracket indicates a whole group of four accessions. The significance of the differences between different accessions are shown only within the same treatment group, and significances between NAC and ACC plants are shown only between the corresponding age groups

Even though PSII activity declined by about $20 \%$ during the 45 -min high light illumination in the absence of lincomycin at $22^{\circ} \mathrm{C}$ (Fig. $1 \mathrm{~A}$ ), a similar illumination treatment did not cause a decline in the net rate of $\mathrm{CO}_{2}$ assimilation, measured per leaf area (Fig. 5). The maximum assimilation rates varied between the accessions, and the values (Fig. 5) and the chlorophyll content of the leaves (Fig. 4A) showed similar order between the accessions, with Rschew highest and Coimbra and Columbia-0 low, especially in NAC plants. Cold-acclimation caused a decrease in the rate of $\mathrm{CO}_{2}$ assimilation in high light at $22^{\circ} \mathrm{C}$ in all four accessions (Fig. 5). 


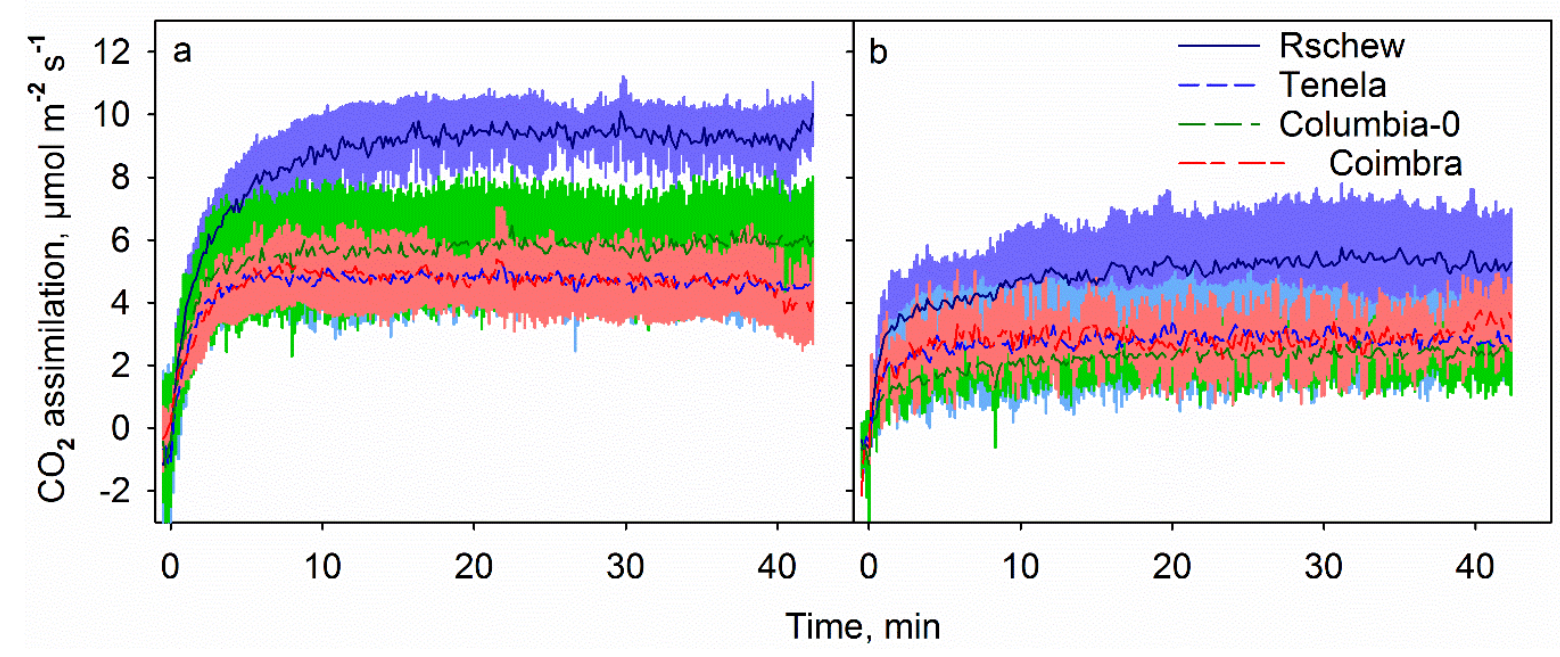

Fig. $5 \mathrm{Net} \mathrm{CO}_{2}$ assimilation rates at $22^{\circ} \mathrm{C}$ during 42-min illumination in high light (PPFD $2000 \mu \mathrm{mol} \mathrm{m}$ ${ }^{2} \mathrm{~s}^{-1}$ ), measured from intact light-acclimated leaves of non-acclimated (a) or cold-acclimated (b) $A$. thaliana accessions (Rschew, Tenela, Columbia-0 and Coimbra). The lines show averages and the colored areas show SD values from at least three biological replicates

\section{5. ${ }^{1} \mathrm{O}_{2}$ production in thylakoid membranes}

To see if the physiological differences of the accessions lead to differences in the production of ${ }^{1} \mathrm{O}_{2}$, we measured the rate of ${ }^{1} \mathrm{O}_{2}$ production in isolated thylakoid membranes of NAC and ACC plants at $20{ }^{\circ} \mathrm{C}$ and at $4{ }^{\circ} \mathrm{C}$. At $20^{\circ} \mathrm{C}$, thylakoids isolated from ACC plants produced more ${ }^{1} \mathrm{O}_{2}$ than those isolated from NAC plants but the difference was statistically significant only in the case of Coimbra (Fig. 6). In both NAC and ACC thylakoids, production of ${ }^{1} \mathrm{O}_{2}$ was slightly slower at $4{ }^{\circ} \mathrm{C}$ than at $20^{\circ} \mathrm{C}$, but statistically significant difference in ${ }^{1} \mathrm{O}_{2}$ production was observed only in ACC Coimbra.

Interestingly, the production of ${ }^{1} \mathrm{O}_{2}$ by ACC thylakoids at $4{ }^{\circ} \mathrm{C}$ did not significantly differ from that of NAC thylakoids (Fig. 6).

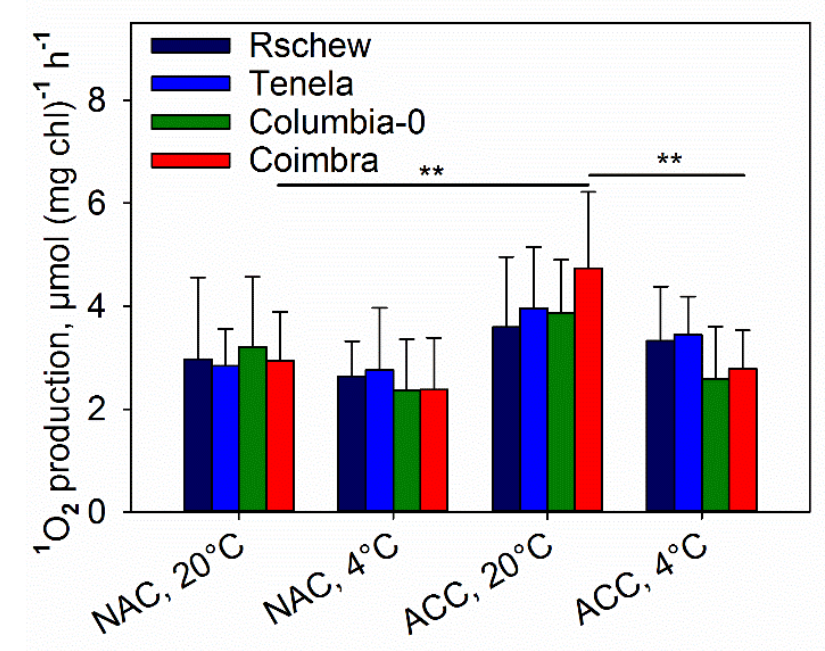

Fig. 6 Production of ${ }^{1} \mathrm{O}_{2}$ in high light (PPFD $4000 \mu \mathrm{mol} \mathrm{m} \mathrm{m}^{-2} \mathrm{~s}^{-1}$ ) at $20^{\circ} \mathrm{C}$ or $4{ }^{\circ} \mathrm{C}$ in thylakoid membranes isolated from non-acclimated (NAC) or cold-acclimated (ACC) A. thaliana accessions (Rschew, Tenela, Columbia- 0 and Coimbra). ${ }^{1} \mathrm{O}_{2}$ was measured with a histidine-based method. The error bars show SD values from at least four biological replicates. Statistically significant differences are marked with ** $(P<0.05)$. The significances of the differences between different accessions are shown only within 
the same treatment group, and significances between NAC and ACC plants are shown only between the corresponding temperatures

Modulation of charge recombination reactions in PSII by cold-acclimation has been suggested to lead to diminished ${ }^{1} \mathrm{O}_{2}$ production (Ivanov 2008). To assess the recombination reactions, thermoluminescence was measured from the same thylakoid membranes used for the ${ }^{1} \mathrm{O}_{2}$ assay. In all samples, the peak of the B-band, measured in the absence of DCMU, was between $25^{\circ} \mathrm{C}$ and 28 ${ }^{\circ} \mathrm{C}$ whereas the Q-band (measured in the presence of DCMU) peaked around $7-9{ }^{\circ} \mathrm{C}$ with no systematic differences between accessions or between NAC and ACC plants (Fig. 7). However, the thermoluminescence yield of the B-band was $4-46 \%$ and the yield of the Q-band $26-46 \%$ lower for the ACC than NAC plants (relative peak intensities are listed in the legend of Fig. 7).

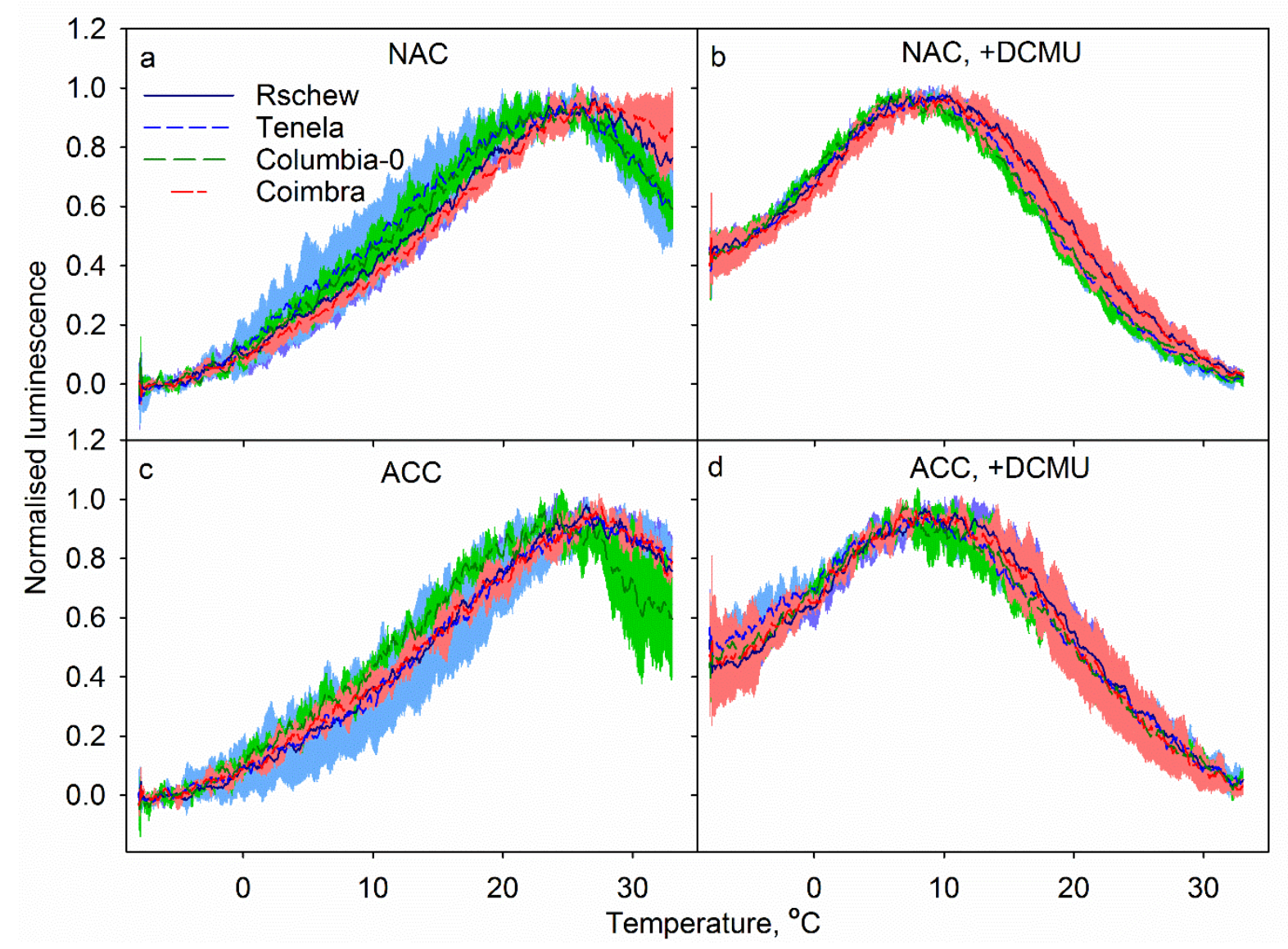

Fig. 7 Normalized thermoluminescence bands in the absence $(a, c)$ or in the presence of DCMU $(b, d)$ measured from thylakoid membranes of non-acclimated (NAC; $a-b$ ) or cold-acclimated (ACC; $c-d) A$. thaliana accessions (Rschew, Tenela, Columbia- 0 and Coimbra). The colored areas show SD values from at least three biological replicates. Maximum luminescence intensities (arbitrary units; \pm SD) were $2.1(0.60), 1.8(0.45), 1.7(0.15)$ and $2.8(0.21)$ for Rschew, Tenela, Columbia-0 and Coimbra, respectively, in (a), $2.5(0.77), 2.2(0.23), 2.2(0.17)$ and $2.6(0.39)$ in (b), $2.0(0.26), 1.5(0.20), 1.4$ $(0.25)$ and $1.5(0.2)$ in (c) and $1.8(0.65), 1.2(0.41), 1.6(0.16)$ and $1.9(0.08)$ in (d) 


\section{Discussion}

\subsection{The damaging reaction of photoinhibition in vivo is slower at $4{ }^{\circ} \mathrm{C}$ than at 22 ${ }^{\circ} \mathrm{C}$}

Temperature affects the rate of the damaging reaction of photoinhibition. To get a comprehensive understanding, we used two parallel methods for measuring photoinhibition of PSII, i.e. the chlorophyll $a$ fluorescence parameter, $\mathrm{F}_{\mathrm{V}} / \mathrm{F}_{\mathrm{M}}$, and PSII-dependent oxygen evolution measured from thylakoids isolated from the treated leaves. Comparison of the present data obtained from the NAC plants of all accessions show a clear trend of slower photoinhibition at $4{ }^{\circ} \mathrm{C}$ than at $22{ }^{\circ} \mathrm{C}$ (Table 1 ), although the fluorescence data do not show statistically significant differences in accessions Rschew and Tenela (Table 1; Fig. 2). A slight increase in the rate of the damaging reaction at higher temperatures corroborates earlier in vitro (Aro et al. 1990; Tyystjärvi et al. 1994) and in vivo (Tyystjärvi 2013) results. These findings suggest that the excitation pressure hypothesis (see Kornyeyev et al., 2003) is not a valid explanation for photoinhibition of PSII.

The data discussed above contrast with the findings of Tsonev and Hikosaka (2003) and Kornyeyev et al. (2003) who observed faster decline in $\mathrm{F}_{\mathrm{V}} / \mathrm{F}_{\mathrm{M}}$ at low than at optimal temperature. It is possible that the discrepancy originates from the methods used for assessing photoinhibition. $\mathrm{FV}_{\mathrm{V}} / \mathrm{F}_{\mathrm{M}}$ may reflect low-temperature-induced fluorescence quenching that does not relax during a typical darkadaptation time (20-60 $\mathrm{min}$ ). Such slowly relaxing $F_{V} / F_{M}$ might be related to the sustained $N P Q$ that develops in some evergreen species at low temperatures (for a review, see Verhoeven 2014) and might be important also in A. thaliana (Malnoë et al. 2018). Therefore, especially in studies of coldacclimation, use of oxygen evolution as a proxy for photoinhibition is advisable.

Due to the fact that light absorption continues but carbon fixation and other enzymatic reactions slow down, light can possess a severe stress for plants (see e.g. Alboresi et al. 2011), even though the rate of light-induced damage to PSII is not accelerated at low temperatures (Table 1; Fig. 3). As low temperature commonly slows down the enzymatic reactions of concurrent recovery of photoinhibitory damage (Greer et al. 1986; Aro et al. 1990) and ROS produced at low temperature may specifically inhibit translation in the chloroplast (Kojima et al. 2009), net loss of PSII activity during illumination at temperatures below the optimum occurs (Tyystjärvi and Aro 1990; Öquist et al. 1993; Allakhverdiev and Murata 2004). The results of the present study confirm faster loss of PSII activity at $4{ }^{\circ} \mathrm{C}$ than at $22^{\circ} \mathrm{C}$ when no protein synthesis inhibitor was used (Fig. $1 \mathrm{~A}-\mathrm{B}$ ) that corresponds, taking into account the rate of the damage (Table 1 ), to slower repair cycle of PSII at 4 ${ }^{\circ} \mathrm{C}$ than at $22{ }^{\circ} \mathrm{C}$.

\subsection{Cold-acclimation may increase the tolerance against photoinhibition in $A$. thaliana accessions}

Plants' capacity to cold-acclimate vary greatly (e.g. Hannah et al. 2006, Hasdai et al. 2006, Oakley et al. 2018) and a correlation exists between the distance of a species or accession from the equator and their capacity to gain cold-tolerance (Hannah et al. 2006; Mishra et al. 2011; Lukas et al. 2014). The $\mathrm{LT}_{50}$ (lethal temperatures at which $50 \%$ of tissue damage occurs as measured by electrolyte leakage) has been reported to be $-5.7{ }^{\circ} \mathrm{C},-7.7{ }^{\circ} \mathrm{C},-5.2^{\circ} \mathrm{C}$ and $4.6^{\circ} \mathrm{C}$ for Rschew, Tenela, Columbia- 0 and Coimbra, respectively (Hannah et al. 2006; Mishra et al. 2011). Two weeks of cold-acclimation at $4{ }^{\circ} \mathrm{C}$ can significantly increase the cold-tolerance in Rschew, Tenela and Columbia- 0 (to $-10.6^{\circ} \mathrm{C},-12.2$ ${ }^{\circ} \mathrm{C}$ and $-10.3^{\circ} \mathrm{C}$, respectively), however, Coimbra is able to decrease the $\mathrm{LT}_{50}$ only by about $1.5^{\circ} \mathrm{C}$ (Hannah et al. 2006).

Cold-acclimation slowed down photoinhibition of PSII by slowing down the damaging reaction of photoinhibition of PSII in all accessions when measured with $\mathrm{Fv}_{\mathrm{V}} / \mathrm{F}_{\mathrm{M}}$, and the difference was 
statistically significant in the two most cold-tolerant accessions Rschew and Tenela (Fig. 2; Table 1), similarly as reported previously for cyanobacteria (Vonshak and Novoplansky 2008). Oxygen evolution data, in turn, showed protection by cold-acclimation only in the accessions Columbia- 0 and Coimbra, which can be considered as intermediate cold-tolerant and cold-susceptible, respectively.

The results suggest that cold-acclimation can harness plants against photoinhibition. However, in the accessions used in the present study the differences were not big, and Rschew and Tenela were actually more susceptible to photoinhibition after cold-acclimation, when oxygen evolution was used to quantify photoinhibition, though the difference was not statistically significant (Fig. 3; Table 1). This may indicate that the acclimation that induces cold-tolerance in A. thaliana does not primarily provide protection against PSII damage. It should be noted, however, that in the present study plants were grown under moderate light (PPFD $100 \mu \mathrm{mol} \mathrm{m}^{-2} \mathrm{~s}^{-1}$ ), which may impair their capacity to respond to high-light-treatments.

In addition, even though cold-acclimation seemed to attenuate photoinhibition also in the absence of lincomycin, the differences were neither large nor statistically significant (Fig. 1B-C), suggesting that in the natural accessions used, enhancement of the repair reactions of PSII is not a prominent factor in cold-tolerance. In fact, photoinhibition (or decrease in photosynthesis in more general) has been suggested not to be the cause of decreased productivity but regulation responding to diminished sink demand (see Adams et al. 2013). Accordingly, $\mathrm{CO}_{2}$ assimilation at $22^{\circ} \mathrm{C}$ (Fig. 5) did not correlate with the amount of photoinhibition in any NAC accessions (Figs. 1-3). In addition, net $\mathrm{CO}_{2}$ assimilation was slower in cold-acclimated leaves than in their NAC counterparts; however, carbon fixation at $4{ }^{\circ} \mathrm{C}$ was not measured. The lack of change in the rate of carbon fixation under strong light also suggests that $A$. thaliana leaves contain more PSIl than needed to saturate the needs of the carbon fixation reactions in high light (see also Chow 2001).

\subsection{Decrease in thermoluminescence yield did not lower ${ }^{1} \mathrm{O}_{2}$ production}

What causes the cold-acclimation-induced alleviation of photoinhibition? ${ }^{1} \mathrm{O}_{2}$ is produced mainly in the recombination reactions of PSII, and it has been suggested to cause the photodamage to PSII (e.g. Vass 2012). Increased production of ${ }^{1} \mathrm{O}_{2}$ in the npq1/ut2 mutant of $A$. thaliana leads to oxidative damage to thylakoid proteins in high light at $10^{\circ} \mathrm{C}$ (Alboresi et al. 2011). In different plants species including $A$. thaliana (Janda et al. 2000; Ivanov et al. 2001; Sane et al. 2003), cold-acclimation causes a decrease in the redox gap between the $Q_{A}$ and $Q_{B}$ electron acceptors of PSII, which favors an indirect, non-radiative recombination route (Rappaport and Lavergne 2009) for the elimination of the charge in $\mathrm{Q}_{A}{ }^{-}$(Ivanov 2008). The indirect route does not produce ${ }^{1} \mathrm{O}_{2}$ and, therefore, the observed decrease in photoinhibition caused by cold-acclimation might be due to a decrease in ${ }^{1} \mathrm{O}_{2}$ production (for a more comprehensive discussion about the relationship between recombination reactions and ${ }^{1} \mathrm{O}_{2}$, see Krieger-Liszkay et al. 2008; Vass and Cser 2009). Accordingly, Ramel et al. (2012) observed a decrease in both production of ${ }^{1} \mathrm{O}_{2}$ and oxidation of beta-carotene after $99 \mathrm{~h}$ at $7{ }^{\circ} \mathrm{C}$. However, ${ }^{1} \mathrm{O}_{2}$ was measured with Singlet Oxygen Sensor Green in white light, a condition that has been shown to induce ${ }^{1} \mathrm{O}_{2}$ production by the sensor itself (e.g. Ragás et al. 2009).

We did not observe shifts in the peak temperatures of the thermoluminescence bands (Fig. 7). Discrepancy with the earlier data (e.g. Sane et al. 2003) may result from different durations of the cold-acclimation treatments. We cold-acclimated the $A$. thaliana accessions for 14 days which is enough for cold-tolerance (e.g. Mishra et al. 2011; Mishra et al. 2014), but stronger alleviation of photoinhibition was reported when each leaf developed at low temperature (Strand et al. 1999; Gray et al. 2003). However, we did observe a decrease in the thermoluminescence yield for both B-and Qbands, resembling that reported by Ivanov et al. (2001) and Sane et al. (2003). The intensity of the Bband decreased only little, $4 \%$, in Rschew but the decrease was more remarkably in Tenela (18\%), Columbia-0 (20\%) and Coimbra (46\%). We also observed strong alleviation of photoinhibition in the cold-acclimated Coimbra. However, in other accessions or in the Q-band, the decrease in the 
intensity did not correlate with the rate of photoinhibition (Fig. 7, Table 1). Furthermore, coldacclimation did not cause a decrease in the capacity of the thylakoids to produce ${ }^{1} \mathrm{O}_{2}$ during illumination (Fig. 6).

If the rate of repair is insignificant at low temperatures, then the results from illumination treatments without an inhibitor of (chloroplast) protein synthesis could be taken to represent the amount of damage to PSII. However, in the present data, addition of lincomycin clearly increased photoinhibition, indicating that the repair cycle is active even at $4{ }^{\circ} \mathrm{C}$ in NAC plants (Figs. 1-2). Also the finding that genes coding for a protease involved in PSII repair cycle $(\mathrm{FtsH})$ are up-regulated at low temperature (Soitamo et al. 2008) support this view. Consequently, it remains unclear whether the (proposed) diminished ${ }^{1} \mathrm{O}_{2}$ production by modified recombination reactions (Ivanov at al. 2001; Sane et al. 2003) decreases PSII damage or protects the repair reactions (Kojima et al. 2009; Nishiyama et al. 2011).

\subsection{Sensitivity to ROS does not equal sensitivity to photoinhibition of PSII}

The roles of ROS in the cold-acclimation-induced protection against photoinhibition are interesting also with regard to the mechanism of photoinhibition. The $k_{P I}$ values of the four accessions, measured by both $\mathrm{Fv}_{\mathrm{V}} / \mathrm{F}_{\mathrm{M}}$ and oxygen evolution, were mostly in the order Rschew $<$ Tenela $<$ Columbia- $0<$ Coimbra (Table 1). Furthermore, Coimbra was clearly more susceptible to the damage caused by high light than the other accessions when the PSII repair cycle was allowed to run (Fig. 1). Thus, the two cold-tolerant accessions were somewhat more tolerant to photoinhibition than the other two accessions (Columbia- 0 and Coimbra). Previously, it has been shown that Tenela is sensitive to oxidative stress (Brosché et al. 2010), which is probably linked to increased production of hydrogen peroxide at low temperatures (Distelbarth et al. 2013). However, in our study nonacclimated Tenela was not particularly sensitive to photoinhibition of PSII (Figs. 1-3), which supports the suggestion that oxidative stress and photoinhibition may not be related (Hakkila et al. 2013). Also, the rate of light-induced damage to PSII may not be defined by ROS but rather direct light absorption by the oxygen evolving complex of PSII (Hakala et al. 2005; Ohnishi et al. 2005).

Furthermore, the production of ${ }^{1} \mathrm{O}_{2}$ by isolated thylakoid membranes did not correlate with the $\mathrm{k}_{\mathrm{PI}}$ values (Fig. 8A), suggesting that ${ }^{1} \mathrm{O}_{2}$ is not a decisive factor in photoinhibition tolerance of $A$. thaliana accessions.

Rather than reflecting the ability to resist direct damage by ROS, the sensitivity to oxidative stress may also be governed by a genetic program (Brosché et al. 2010). Hydrogen peroxide, which has a relatively long lifetime in cells, is an important signaling molecule (for a review see e.g. Černý et al. 2018). Further complications in the roles of ROS in cold-acclimation are exemplified by discrepant findings about the relationship between ROS metabolism and freezing tolerance (Distelbarth et al. 2013; Hashempour et al. 2014).

\subsection{Do flavonols quench ${ }^{1} \mathrm{O}_{2}$ and/or protect plants from photoinhibition?}

Synthesis of many flavonol species is induced in coldness (e.g. Schulz et al. 2015) as well as in UV light (e.g. Hectors et al. 2014). Flavonols are able to physically and chemically quench ${ }^{1} \mathrm{O}_{2}$ in vitro (Tournaire et al. 1993), and it has been suggested that they function as ${ }^{1} \mathrm{O}_{2}$ quenchers also in vivo (Pollastri and Tattini 2011; Majer et al. 2014). Accordingly, Havaux and Kloppstech (2001) reported that mutants unable to synthetize anthocyanins and flavonols had lower $F_{V} / F_{M}$ values and more lipid peroxidation at low temperatures than wild-type plants.

Although in Columbia- 0 and Coimbra one can see a positive correlation between flavonols and the rate constant of photoinhibition, suggesting that quenching of ${ }^{1} \mathrm{O}_{2}$ by flavonols can in some accessions protect against photoinhibition, general correlation was not found (Fig. 8B). In addition, even though cold-acclimation increased the amount of flavonols in all accessions tested here (Fig. 4), 
the rate of ${ }^{1} \mathrm{O}_{2}$ production by isolated thylakoid membranes did not depend on the flavonol content of the leaf (Fig. 6).

Of course, the optical method used in the present study mainly reflects the amount of epidermal flavonols. Therefore, the role of flavonols, both inside and outside of chloroplasts, in cold-tolerance requires more research. Flavonols may be important as freezing inhibitors (Isshiki et al. 2014; Korn et al. 2008). Flavonols may also have regulatory roles (Yin et al. 2014).

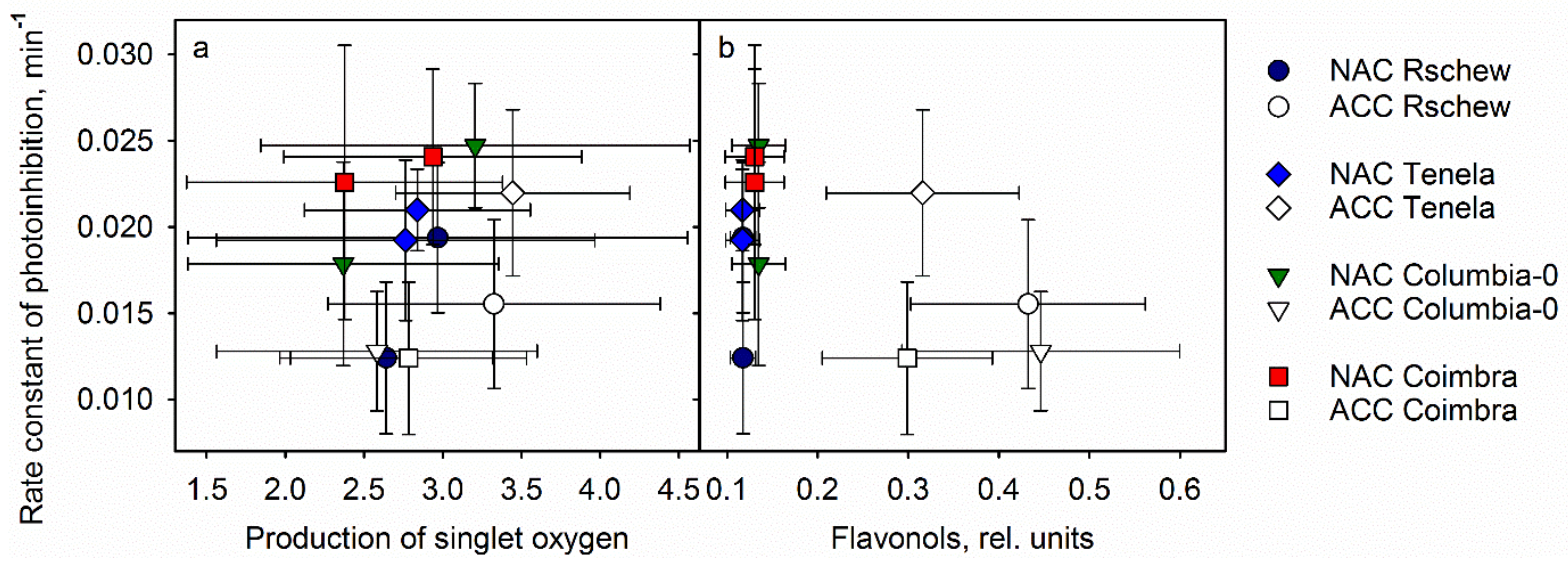

Fig. 8 Rate constant of photoinhibition (quantified as a loss of oxygen evolution capacity of PSII) plotted against production of ${ }^{1} \mathrm{O}_{2}$ by thylakoid membranes (a) and the amount of epidermal flavonols (b) in four $A$. thaliana accessions (Rschew, Tenela, Columbia-0 and Coimbra) after 14 days of cold acclimation at $4{ }^{\circ} \mathrm{C}$ (ACC) or from control plants of similar ages grown at $21^{\circ} \mathrm{C}$ (NAC). The data are from Figs. 4 and 6 and from Table 1

\section{Conflict of interest}

The authors declare that they have no conflict of interest.

\section{References}

Abat JK, Deswal R (2009) Differential modulation of S-nitrosoproteome of Brassica juncea by low temperature: change in S-nitrosylation of Rubisco is responsible for the inactivation of its carboxylase activity. Proteomics. 9:4368-4380.

Adams WW, Muller O, Cohu CM, Demmig-Adams B (2013) May photoinhibition be a consequence, rather than a cause, of limited plant productivity? Photosynth. Res. 117:31-44.

Agati G, Matteini P, Goti A, Tattini M (2007) Chloroplast-located flavonoids can scavenge singlet oxygen. New Phytol. 174:77-89.

Alboresi A, Dall'Osto L, Aprile A, Carillo P, Roncaglia E, Cattivelli L, Bassi R (2011) Reactive oxygen species and transcript analysis upon excess light treatment in wild-type Arabidopsis thaliana vs a photosensitive mutant lacking zeaxanthin and lutein. BMC Plant Biol. 11:62.

Allakhverdiev S, Murata N (2004) Environmental stress inhibits the synthesis de novo of proteins involved in the photodamage-repair cycle of Photosystem II in Synechocystis sp PCC 6803. Biochim. Biophys. Acta Bioenerg. 1657:23-32. 
Arellano JB, Naqvi KR (2016) Endogenous singlet oxygen photosensitizers in plants. In Singlet oxygen: Applications in Biosciences and Nanosciences, Edited by Nonell, S. and Flors, C. pp. 239-269. The Royal Society of Chemistry.

Aro EM, Hundal T, Carlberg I, Andersson B (1990) In vitro studies on light-induced inhibition of Photosystem II and D1-protein degradation at low temperatures. Biochim. Biophys. Acta. 1019:269275.

Brosché M, Merilo E, Mayer F, Pechter P, Puzõrjova I, Brader G, Kangasjärvi J, Kollist H (2010) Natural variation in ozone sensitivity among Arabidopsis thaliana accessions and its relation to stomatal conductance. Plant Cell Environ. 33:914-925.

Černý M, Habánová H, Berka M, Luklová M, Brzobohatý B (2018) hydrogen peroxide: its role in plant biology and crosstalk with signalling networks. Int. J. Mol. Sci. 19:2812.

Chow WS (2001) The photoinactivation of photosystem II in leaves: a personal perspective. J. Photosci. 8:43-53.

Crosatti C, Rizza F, Badeck FW, Mazzucotelli E, Cattivelli L (2013) Harden the chloroplast to protect the plant. Physiol. Plant. 147:55-63.

Distelbarth H, Nägele T, Heyer AG (2013) Responses of antioxidant enzymes to cold and high light are not correlated to freezing tolerance in natural accessions of Arabidopsis thaliana. Plant Biol. 15:982990.

Gray GR, Savitch LV, Ivanov AC, Huner NPA (1996) Photosystem II excitation pressure and development of resistance to photoinhibition II. Adjustment of photosynthetic capacity in winter wheat and winter rye. Plant Physiol. 110:61-71.

Gray GR, Hope BJ, Qin XQ, Taylor BG, Whitehead CL (2003) The characterization of photoinhibition and recovery during cold acclimation in Arabidopsis thaliana using chlorophyll fluorescence imaging. Physiol. Plant. 119:365-375.

Greer DH, Berry JA, Björkman O (1986) Photoinhibition of photosynthesis in intact bean leaves: role of light and temperature, and requirement for chloroplast-protein synthesis during recovery. Planta. 168:253-60.

Grennan AK, Ort DR (2007) Cool temperatures interfere with D1 synthesis in tomato by causing ribosomal pausing. Photosynth Res. 94:375-385.

Hakala M, Tuominen I, Keränen M, Tyystjärvi T, Tyystjärvi E (2005) Evidence for the role of the oxygen-evolving manganese complex in photoinhibition of Photosystem II. Biochim. Biophys. Acta. 1706:68-80.

Hakkila K, Antal T, Rehman AU, Kurkela J, Wada H, Vass I, Tyystjärvi T, Tyystjärvi E (2013) Oxidative stress and photoinhibition can be separated in the cyanobacterium Synechocystis sp PCC 6803. Biochim. Biophys. Acta. 1837:217-225.

Hannah MA, Wiese D, Freund S, Fiehn O, Heyer AG, Hincha DK (2006) Natural genetic variation of freezing tolerance in Arabidopsis. Plant. Physiol. 142:98-112.

Hasdai M, Weiss B, Levi A, Samach A, Porat R (2006) Differential responses of Arabidopsis ecotypes to cold, chilling and freezing temperatures. Ann. Appl. Biol. 148:113-120. 
Hashempour A, Ghasemnezhad M, Ghazvini RF, Sohani MM (2014) Olive (Olea europaea L.) freezing tolerance related to antioxidant enzymes activity during cold acclimation and non acclimation. Acta Physiol. Plant. 36:3231-3241.

Havaux M, Kloppstech K (2001) The protective functions of carotenoid and flavonoid pigments against excess visible radiation at chilling temperature investigated in Arabidopsis npq and tt mutants. Planta. 213:953-966.

Hectors K, Van Oevelen S, Geuns J, Guisez Y, Jansen MAK, Prinsen E (2014) Dynamic changes in plant secondary metabolites during UV acclimation in Arabidopsis thaliana. Physiol. Plant. 152:219-230.

Hurry VM, Malmberg G, Gardeström P, Öquist G (1994) Effects of a short-term shift to lowtemperature and of long-term cold hardening on photosynthesis and ribulose-1,5-bisphosphate carboxylase oxygenase and sucrose-phosphate synthase activity in leaves of winter rye (Secalecereale L). Plant Physiol. 98:1105-1114.

Isshiki R, Galis I, Tanakamaru S (2014) Farinose flavonoids are associated with high freezing tolerance in fairy primrose (Primula malacoides) plants. J. Integr. Plant Biol. 56:181-188.

Ivanov AG, Rosso D, Savitch LV, Stachula P, Rosembert M, Öquist G, Hurry V, Hüner NPA (2012) Implications of alternative electron sinks in increased resistance of PSII and PSI photochemistry to high light stress in cold-acclimated Arabidopsis thaliana. Photosynth. Res. 113:191-206.

Ivanov AG, Sane PV, Hurry V, Öquist G, Huner NPA (2008) Photosystem II reaction centre quenching: mechanisms and physiological role. Photosynth. Res. 98:565-574.

Ivanov AG, Sane PV, Krol M, Gray GR, Balseris A, Savitch LV, Öquist G, Huner NPA (2006) Acclimation to temperature and irradiance modulates PS II charge recombination. FEBS Lett. 580:2797-2802.

Ivanov AG, Sane PV, Zeinalov Y, Malmberg G, Gardeström P, Huner NPA, Öquist G (2001) Photosynthetic electron transport adjustments in overwintering Scots pine (Pinus sylvestris L.). Planta. 213:575-585.

Janda T, Szalai G, Páldi E. (2000) Thermoluminescence investigation of low temperature stress in maize. Photosynthetica. 38:635-639.

Janda T, Szalai G, Papp N, Pál M, Páldi E (2004) Effects of freezing on thermoluminescence in various plant species. Photochem. Photobiol. 80:525-530.

Karonen M, Mattila H, Huang P, Mamedov F, Styring S, Tyystjärvi E (2014) A tandem mass spectrometric method for singlet oxygen measurement. Photochem. Photobiol. 90:965-971.

Kojima K, Oshita M, Nanjo Y, Kasai K, Tozawa Y, Hayashi H, Nishiyama Y. (2009) Oxidation of elongation factor $\mathrm{G}$ inhibits the synthesis of the D1 protein of photosystem II. Mol. Microbiol. 65:936-947.

Korn M, Peterek S, Mock HP, Heyer AG, Hincha DK (2008) Heterosis in the freezing tolerance, and sugar and flavonoid contents of crosses between Arabidopsis thaliana accessions of widely varying freezing tolerance. Plant Cell Environ. 31:813-827.

Kornyeyev D, Holaday S, Logan B (2003) Predicting the extent of Photosystem II photoinactivation using chlorophyll a fluorescence parameters measured during illumination. Plant Cell Physiol. 44:1064-1070. 
Krause GH, Carouge N, Garden H (1999) Long-term effects of temperature shifts on xanthophyll cycle and photoinhibition in spinach (Spinacia oleracea). Aust. J. Plant Physiol. 26:125-134.

Krieger-Liszkay A, Fufezan C, Trebst A (2008) Singlet oxygen production in photosystem II and related protection mechanism. Photosynth. Res. 98: 551-564.

Lukatkin AS, Brazaitytė A, Bobinas Č, Duchovskis P (2012) Chilling injury in chilling-sensitive plants: a review. Žemdirbystè-Agriculture. 99:111-124.

Liu X, Zhou Y, Xiao J, Bao F (2018) Effects of chilling on the structure, function and development of chloroplasts. Front. Plant Sci. 9:1715.

Lukas V, Mishra A, Mishra KB, Hajslova J (2013) Mass spectrometry-based metabolomic fingerprinting for screening cold tolerance in Arabidopsis thaliana accessions. Anal. Bioanal. Chem. 405:2671-2683.

Majer P, Neugart S, Krumbein A, Schreiner M, Hideg É (2014) Singlet oxygen scavenging by leaf flavonoids contributes to sunlight acclimation in Tilia platyphyllos. Environ. Exper. Bot. 100:1-9.

Malnoë A, Schultink A, Shahrasbi S, Rumeau D, Havaux M, Niyogi KK (2018) The Plastid Lipocalin LCNP Is Required for Sustained Photoprotective Energy Dissipation in Arabidopsis. Plant Cell. 30:196208.

Mattila H, Khorobrykh S, Havurinne V, Tyystjärvi E (2015) Reactive oxygen species: Reactions and detection from photosynthetic tissues. J. Photochem. Photobiol. B. 152:176-214.

Mishra A, Mishra KB, Höermiller II, Heyer AG, Nedbal L (2011) Chlorophyll fluorescence emission as a reporter on cold tolerance in Arabidopsis thaliana accessions. Plant Signal. Behav. 6:301-310.

Mishra A, Heyer AG, Mishra KB (2014) Chlorophyll fluorescence emission can screen cold tolerance of cold acclimated Arabidopsis thaliana accessions. Plant Methods 10:38.

Mishra KB, Mishra A, Kubásek J, Urban O, Heyer AG, Govindjee (2019) Low temperature induced modulation of photosynthetic induction in non-acclimated and cold-acclimated Arabidopsis thaliana: chlorophyll a fluorescence and gas-exchange measurements. Photosynth. Res. 139:123-143.

Moan J (1990) On the diffusion length of singlet oxygen in cells and tissues. J. Photochem. Photobiol. B. 6:343-347.

Murata N, Ishizaki-Nishizawa O, Higashi S, Hayashi H, Tasaka Y, Nishida I (1992) Genetically engineered alteration in the chilling sensitivity of plants. Nature. 356:710-713.

Nath K, Jajoo A, Poudyal RS, Timilsina R, Park YS, Aro EM, Nam HG, Lee CH (2013) Towards a critical understanding of the photosystem II repair mechanism and its regulation during stress conditions. FEBS Lett. 587:3372-3381.

Nishiyama Y, Allakhverdiev SI, Murata N (2011) Protein synthesis is the primary target of reactive oxygen species in the photoinhibition of photosystem II. Phys. Plant. 142:35-46.

Oakley CG, Savage L, Lotz S, Larson GR, Thomashow MF, Kramer DM, Schemske DW (2018) Genetic basis of photosynthetic responses to cold in two locally adapted populations of Arabidopsis thaliana. J Exp Bot. 69:699-709.

Ohnishi N, Allakhverdiev SI, Takahashi S, Higashi S, Watanabe M, Nishiyama Y, Murata N (2005) Twostep mechanism of photodamage to Photosystem II: Step 1 occurs at the oxygen-evolving complex and step 2 occurs at the photochemical reaction center. Biochemistry. 44:8494-8499. 
Öquist G, Hurry V, Huner NPA (1993) The temperature-dependence of the redox state of $Q(A)$ and susceptibility of photosynthesis to photoinhibition. Plant Physiol. Biochem. 31:683-691.

Preston JC, Sandve SR (2013) Adaptation to seasonality and the winter freeze. Front. Plant Sci. 4:167.

Pollastri S, Tattini M (2011) Flavonols: old compounds for old roles. Ann. Bot. 108:1225-1233.

Porra RJ, Thompson WA, Kriedemann PE (1989) Determination of accurate extinction coefficients and simultaneous equations for assaying chlorophylls $a$ and $b$ extracted with four different solvents: verification of the concentration of chlorophyll standards by atomic absorption spectroscopy. Biochim. Biophys. Acta. 975:384-394.

Ramel F, Birtic S, Cuiné S, Triantaphylidès C, Ravanat J, Havaux M (2012) Chemical quenching of singlet oxygen by carotenoids in plants. Plant Physiol. 158:1267-1278.

Ragás X, Jiménez-Banzo A, Sánchez-García D, Batllori X, Nonell S (2009) Singlet oxygen photosensitisation by the fluorescent probe Singlet Oxygen Sensor Green(R). Chem. Commun. 20:2920-2922.

Rappaport F, Lavergne J (2009) Thermoluminescence: theory. Photosynth. Res. 101:205-216.

Rehman AU, Cser K, Sass L, Vass I (2013) Characterization of singlet oxygen production and its involvement in photodamage of photosystem II in the cyanobacterium Synechocystis PCC 6803 by histidine-mediated chemical trapping. Biochim. Biophys. Acta. 1827:689-698.

Rogalski M, Schöttler MA, Thiele W, Schulze WX, Bock R (2008) Rpl33, a nonessential plastidencoded ribosomal protein in tobacco, is required under cold stress conditions. Plant Cell. 20:22212237.

Salonen M, Aro EM, Rintamäki E (1998) Reversible phosphorylation and turnover of the D1 protein under various redox states of Photosystem II induced by low temperature photoinhibition. Photosynth. Res. 58:143-151.

Sane PV, Ivanov AG, Hurry V, Huner NPA, Öquist G (2003) Changes in the redox potential of primary and secondary electron-accepting quinones in photosystem II confer increased resistance to photoinhibition in low-temperature-acclimated Arabidopsis. Plant Physiol. 132:2144-2151.

Saunders JA, McClure JN (1976) The distribution of flavonoids in chloroplasts of twenty five species of vascular plants. Phytochemistry. 15:809-810.

Savitch LV, Massacci A, Gray GR, Huner NPA (2000) Acclimation to low temperature or high light mitigates sensitivity to photoinhibition: roles of the Calvin cycle and the Mehler reaction. Aust. J. Plant Physiol. 27:253-264.

Scheidt HA, Pampel A, Nissler L, Gebhardt R, Huster D (2004) Investigation of the membrane localization and distribution of flavonoids by high-resolution magic angle spinning NMR spectroscopy. Biochim. Biophys. Acta. 1663:97-107.

Shang W, Schmidt M, Feierabend J (2003) Increased capacity for synthesis of the D1 protein and of catalase at low temperature in leaves of cold-hardened winter rye (Secale cereale L.). Planta. 216:865-873.

Soitamo AJ, Piippo M, Allahverdiyeva Y, Battchikova N, Aro EM (2008) Light has a specific role in modulating Arabidopsis gene expression at low temperature. BMC Plant Biol. 8:13. 
Somersalo S, Krause GH (1989) Photoinhibition at chilling temperature: Fluorescence characteristics of unhardened and cold-acclimated spinach leaves. Planta. 177:409-416.

Sonoike K (1999) The different roles of chilling temperatures in the photoinhibition of photosystem I and photosystem II. J. Photochem. Photobiol. B. 48:136-141.

Strand Å, Hurry V, Henkes S, Huner N, Gustafsson P, Gardeström P, Gardeström P, Stitt M (1999) Acclimation of Arabidopsis leaves developing at low temperatures. Increasing cytoplasmic volume accompanies increased activities of enzymes in the Calvin cycle and in the sucrose-biosynthesis pathway. Plant Physiol. 119:1387-1397.

Telfer A, Bishop SM, Phillips D, Barber J (1994) Isolated photosynthetic reaction center of Photosystem II as a sensitizer for the formation of singlet oxygen. Detection and quantum yield determination using a chemical trapping technique. J Biol. Chem. 269:13244-13253.

Theocharis A, Clément C, Barka EA (2012) Physiological and molecular changes in plants grown at low temperatures. Planta. 235:1091-1105.

Tournaire C, Croux S, Maurette T (1993) Antioxidant activity of flavonoids: efficiency of singlet oxygen (1 $\Delta \mathrm{g})$ quenching. J. Photochem. Photobiol. B. 19:215-205.

Triantaphylidès C, Havaux M (2009) Singlet oxygen in plants: production, detoxification and signaling. Trends Plant Sci. 14:219-228.

Tsonev TD, Hikosaka K (2003) Contribution of photosynthetic electron transport, heat dissipation, and recovery of photoinactivated Photosystem II to photoprotection at different temperatures in Chenopodium album leaves. Plant Cell Physiol. 44:828-835.

Tyystjärvi E (1993) Photoinhibition - Struggle between damage and repair of Photosystem II. Doctoral thesis, University of Turku.

Tyystjärvi E (2013) Photoinhibition of Photosystem II. Int. Rev. Cell. Mol. Biol. 300:243-303.

Tyystjärvi E, Aro EM (1990) Temperature-dependent changes In Photosystem-II heterogeneity support a cycle of photosystem-II during photoinhibition. Photosynth. Res. 26:109-117.

Tyystjärvi E, Aro EM (1996) The rate constant of photoinhibition, measured in lincomycin-treated leaves, is directly proportional to light intensity. Proc Natl Acad Sci USA 93:2213-2218.

Tyystjärvi E, Kettunen R, Aro EM (1994) The rate constant of photoinhibition in vitro is independent of the antenna size of Photosystem II but depends on temperature. Biochim. Biophys Acta. 1186:177-185.

Tyystjärvi E, Ovaska J, Karunen P, Aro EM (1989) The nature of light-induced inhibition of Photosystem II in pumpkin (Cucurbita pepo L.) leaves depends on temperature. Plant Physiol. 91:1069-1074.

Tyystjärvi E, Rantamäki S, Tyystjärvi J (2009) Connectivity of Photosystem II is the physical basis of retrapping in photosynthetic thermoluminescence. Biophys. J. 96:3735-3743.

Uemura M, Tominaga Y, Nakagawara N, Shigematsu S, Minamic A, Kawamura Y (2006) Responses of the plasma membrane to low temperatures. Physiol. Plant. 126:81-89.

Vass I (2012) Molecular mechanisms of photodamage in the Photosystem II complex. Biochim.

Biophys. Acta-Bioenerg. 1817:209-217. 
Vass I, Cser K (2009) Janus-faced charge recombinations in Photosystem II photoinhibition. Trends Plant Sci. 14:200-205.

Venema JH, Villerius L, van Hasselt PR (2000) Effect of acclimation to suboptimal temperature on chilling-induced photodamage: comparison between a domestic and a high-altitude wild Lycopersicon species. Plant Sci. 152:153-163.

Verhoeven A (2014) Sustained energy dissipation in winter evergreens. New Phytol. 201:57-65.

Vonshak A, Novoplansky N (2008) Acclimation to low temperature of two Arthrospira platensis (cyanobacteria) strains involves down-regulation of PSII and improved resistance to photoinhibition. J. Phycol. 44:1071-1079.

Yamori W, Hikosaka K, Way DA (2014) Temperature response of photosynthesis in C3, C4, and CAM plants: temperature acclimation and temperature adaptation. Photosynth. Res. 119:101-117.

Yang JS, Wang R, Meng JJ, Bi YP, Xu PL, Guo F, Wan SB, He QW, Li XG (2010) Overexpression of Arabidopsis CBF1 gene in transgenic tobacco alleviates photoinhibition of PSII and PSI during chilling stress under low irradiance. J. Plant Physiol. 167:534-539.

Yin R, Han K, Heller W, Albert A, Dobrev PI, Zažímalová E, Schäffner AR (2014) Kaempferol 3-Orhamnoside-7-O-rhamnoside is an endogenous flavonol inhibitor of polar auxin transport in Arabidopsis shoots. New Phytol. 201:466-475. 